\title{
Appendix
}

\section{Annex C. Computational Aspects of Using GAMS}

\subsection{Introduction to GAMS}

During this presentation, we have solved most of problems using the GAMS (General Algebraic Modelling System) code available on the site www.gams.com. A free student version is available on that site. Different commercial copies for different system platforms are available, too. In early 2003, a new GAMS User Guide was released, expanding on the earlier Guides by Brooke, Kendrick, and Meeraus and, later, Ramen. Succinctly speaking, GAMS is a language for setting up and solving mathematical programming optimization models. It is a compact language simultaneously allowing one to specify the structure of an optimization model, specify and calculate data for the model, solve the model, conduct report writing on a model and perform a comparative static analysis. Any introductory GAMS user guide provides the different steps in programming in that language.

Steps of programming in GAMS:

1. Variable specifications

2. Equation specifications

a. declaration

b. algebraic structure specification

3. Model statement

4. Solve statement

To be more complete, an example of GAMS programming, presented by Dhazn Gillig \& Bruce A. McCarl (Department of Agricultural Economics, Texas A\&M University) at http://agecon.tamu.edu/faculty/mccarl/mccarl.htm is included below.

\subsection{Formulation of a Simple Linear Problem in GAMS}

a) Mathematical model:

$\begin{array}{lllll}\text { Maximize } & 109 \mathrm{X}_{1} & 90 \mathrm{X}_{2} & 115 \mathrm{X}_{3} & \\ \text { Subject to } & \mathrm{X}_{1} & \mathrm{X}_{2} & \mathrm{X}_{3} & \leq 100 \\ & 6 \mathrm{X}_{1} & 4 \mathrm{X}_{2} & 8 \mathrm{X}_{3} & \leq 500 \\ & \mathrm{X}_{1} & \mathrm{X}_{2} & \mathrm{X}_{3} & \geq 0 \text { (non- } \\ & & & & \text { negative) }\end{array}$


b) Structure of the program:

VARIABLES

Z Variable Z ;

POSITIVE VARIABLES

$\mathrm{X} 1 \quad$ Variable X1

X2 Variable X2

X3 Variable X3 ;

EQUATIONS

Equation1 Equation 1

Equation2 Equation 2

Equation3 Equation 3 ;

Equation1..

$\mathrm{Z}=\mathrm{E}=109^{\star} \mathrm{X} 1+90^{\star} \mathrm{X} 2+115^{\star} \mathrm{X} 3$

Equation2

$\mathrm{X} 1+\mathrm{X} 2+\mathrm{X} 3=\mathrm{L}=100$

Equation3

$6^{\star} \mathrm{X} 1+4^{\star} \mathrm{X} 2+8^{\star} \mathrm{X} 3=\mathrm{L}=500$

MODEL Example1 /ALL/;

SOLVE Example1 USING LP MAXIMIZING Z;

As is easy to observe, the sequences of solving the above linear program problem are ordered according to the above GAMS programming steps.

\subsection{Application to Maximum Entropy Models}

\subsubsection{The Jaynes Unbalanced Dice Problem}

This problem has been presented in Part II of this book and outputs displayed in Table 2.1. Here we present a code in GAMS (see Golan et al.,1996) for solving such a simple unidimentional problem.

${ }^{*}$ Derivation of probability structure of unfair dice with the GAMS code:

SET

$$
\text { i index } / 1^{\star} 6 /
$$


parameter

$\mathrm{x}(\mathrm{i})$ support $/ 11$

22

33

44

55

$66 /$;

POSITIVE VARIABLE P(i) probabilities;

VARIABLE OBJ objective;

EQUATIONS

OBJECTIVE entropy objective

ADD additivity constraint

CONSIST consistency equation;

OBJECTIVE..OBJ =E= -sum(i, $\left.\mathrm{P}(\mathrm{i}){ }^{\star} \log (1 . e-9+\mathrm{P}(\mathrm{i}))\right)$;

ADD..SUM(i, $\mathrm{P}(\mathrm{i}))=\mathrm{E}=1$;

CONSIST..SUM(i, $\left.\left(\mathrm{x}(\mathrm{i})^{\star} \mathrm{P}(\mathrm{i})\right)\right)=\mathrm{E}=4.5$;

Model classoc/ALL/;

Solve classoc maximizing OBJ using NLP;

DISPLAY P.L;

DISPLAY OBJ.L;

\subsubsection{Non-Extensive Entropy Econometric Model}

This is a more complex example written by S. Bwanakare (2009) for real world problems, in this case a labour demand model for the Polish economy. More explanations are provided in the following introductory text of the program

\section{Sontext}

Generalized Maximum Entropy Parameter estimation of a labour demand econometric model for Podkarpacki province. Moving along rationale expectation mainstreams, this model estimates long-run and short-run impact of demand labour determinants. However, since this model belongs to the class of ARDL (autoregressive distributed lag) model, exogenous variables are not independent of the error term. Additionally, due to the small data sample available for the Podkarpacki district, assumptions concerning random term distribution becomes unknown. Then, estimation of parameters using classical methods (like the LS) become ineffective. The model below exploits the Generalized Maximum Entropy principle to estimate parameter of the labour demand model. 


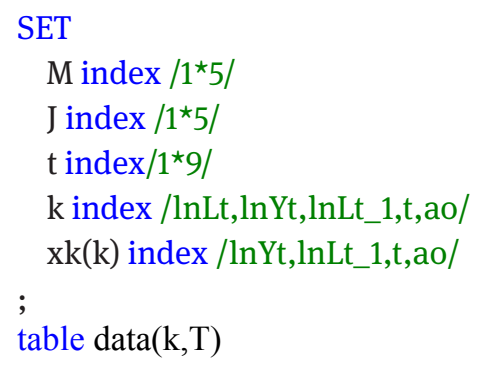

$\begin{array}{llllllllll} & 1 & 2 & 3 & 4 & 5 & 6 & 7 & 8 & 9 \\ \text { LnLt } & 0.0049 & 0.0062 & 0.0026 & -0.0163 & -0.0373 & -0.0137 & -0.0112 & 0.0001 & 0.0051 \\ \text { LnYt } & 0.0936 & 0.0875 & 0.0626 & 0.0301 & 0.0343 & 0.0245 & 0.014 & 0.0212 & 0.0343 \\ \text { LnLt_1 } & 4.5126 & 4.6013 & 4.6826 & 4.7426 & 4.7890 & 4.8606 & 4.8988 & 4.9240 & 4.9451 \\ \mathrm{t} & 1 & 2 & 3 & 4 & 5 & 6 & 7 & 8 & 9 \\ \text { ao } & 1 & 1 & 1 & 1 & 1 & 1 & 1 & 1 & 1\end{array}$

display data;

*\$offtext ;

Positive variables

$\mathrm{P}(\mathrm{xk}, \mathrm{M})$ parameter probabilities

$\mathrm{W}(\mathrm{T}, \mathrm{j})$ error probabilities

sigm standard error on parameters

q parameter tsallis ;

parameter

$\mathrm{V}(\mathrm{t}, \mathrm{j})$ support space for error

Par(xk) parameter estimates

* sigm standard error on parameters

$\mathrm{X}(\mathrm{T}, \mathrm{xk})$ explanatory variables

$\mathrm{Y}\left(\mathrm{T},{ }^{\star}\right)$ dependent variables

$\mathrm{XY}(\mathrm{T}, \mathrm{k})$ all variables

kurt(k) forth moment

* epsilon positive small real

sigmaa(xk) standard error on all variables

sigmaa(xk) sample standard error

$$
\begin{aligned}
& \text { /lnYt } 0.0 \\
& \text { lnLt_1 } 0.0 \\
& \text { t } 0.050 \text { / }
\end{aligned}
$$

Z(M) parameter support / $1-1.000$

$$
2-0.500
$$

30 
40.500

5 1.000/;

$$
\begin{aligned}
& \mathrm{v}(\mathrm{t}, " 1 ")=-3^{\star} \operatorname{sigmaa}(" \operatorname{lnYt} \text { ") ; } \\
& \mathrm{v}\left(\mathrm{t}, 2^{\prime \prime}\right)=-1^{\star} \text { sigmaa("lnYt"); } \\
& \mathrm{v}\left(\mathrm{t}, " 3^{\prime \prime}\right)=0 \text { * } \operatorname{sigmaa}(" \operatorname{lnYt} \text { "); } \\
& \mathrm{v}\left(\mathrm{t}, " 4^{\prime \prime}\right)=1^{\star} \text { sigmaa ("lnYt"); } \\
& \mathrm{v}\left(\mathrm{t}, " 5^{\prime \prime}\right)=3^{\star} \text { sigmaa("lnYt") ; } \\
& \mathrm{v}(\mathrm{t}, " 1 ")=-3^{\star} \operatorname{sigmaa}(\text { "lnLt_1"); } \\
& \mathrm{v}\left(\mathrm{t}, " 2^{\prime \prime}\right)=-1^{\star} \text { sigmaa("lnLt_1"); } \\
& \mathrm{v}\left(\mathrm{t}, " 3^{\prime \prime}\right)=0 \text { *sigmaa("lnLt_1"); } \\
& \mathrm{v}(\mathrm{t}, \text { "4" })=1^{\star} \operatorname{sigmaa}\left(" \operatorname{lnLt} \_1 "\right) \text {; } \\
& \mathrm{v}\left(\mathrm{t}, " 5^{\prime \prime}\right)=3^{\star} \text { sigmaa("lnLt_1") ; } \\
& \mathrm{v}(\mathrm{t}, " 1 ")=-3^{\star} \operatorname{sigmaa}(" \mathrm{t} ") \text {; } \\
& \mathrm{v}(\mathrm{t}, " 2 ")=-1^{\star} \operatorname{sigmaa}(" \mathrm{t} ") \text {; } \\
& \mathrm{v}\left(\mathrm{t}, " 3^{\prime \prime}\right)=0^{\star} \text { sigmaa ("t"); } \\
& \mathrm{v}\left(\mathrm{t}, " 4^{\prime \prime}\right)=1^{\star} \operatorname{sigmaa}(" \mathrm{t} ") \text {; } \\
& \mathrm{v}\left(\mathrm{t}, " 5^{\prime \prime}\right)=3^{\star} \operatorname{sigmaa}(" \mathrm{t} ") \text {; }
\end{aligned}
$$

Display v;

W.1(t, "1")=1/72 ;

W.1(t,"2")=27/72 ;

W.l(t,"3")=16/72 ;

W.1(t,"4")=27/72 ;

W.1(t,"5")=1/72;

parameter

epsilon /0.0001/ ;

$\mathrm{W} . l o(t, \mathrm{j})=$ epsilon ;

W.up $(\mathrm{t}, \mathrm{j})=1$;

p.lo(xk,m)=epsilon;

p.UP(xk,m)=1 ;

* q.lo=epsilon;

Variable OBJ objective ;

$\mathrm{Y}(\mathrm{t}, " \ln L t ")=$ data("lnLt",t);

$\mathrm{X}(\mathrm{t}$, "lnYt") =data("lnYt",t);

$X\left(t, " l n L t \_1 "\right)=$ data $\left(" \operatorname{lnLt} \_1 ", t\right)$;

$\mathrm{X}(\mathrm{t}$, "t") = data("t",t);

$\mathrm{X}(\mathrm{t}$, "ao") =data("ao",t);

q.l=1.5;

display Y, X;

Equations

OBJECTIVE objective function 
ADD1(xk) parameter additivity constraints

ADD2(T) error additivity constraints

CON(T) consistency constraints;

OBJECTIVE..OBJ $=\mathrm{E}=\operatorname{sum}\left(\mathrm{xk}, \operatorname{sum}\left(\mathrm{M}, \quad\left(\mathrm{P}(\mathrm{xk}, \mathrm{M})-\mathrm{P}(\mathrm{xk}, \mathrm{M})^{\star \star} \mathrm{q}\right) /(\mathrm{q}-1)\right)+\operatorname{sum}(\mathrm{T}, \operatorname{Sum}(\mathrm{J}\right.$, $\left.\left.\left.\left(W(T, j)-\left(W(T, j){ }^{\star \star} \mathrm{q}\right) /(\mathrm{q}-1)\right)\right)\right)\right)$;

$\operatorname{ADD} 1(x k) . . s u m(m, P(x k, M))=E=1$;

$\operatorname{ADD} 2(\mathrm{~T}) . . \operatorname{sum}(\mathrm{J}, \mathrm{W}(\mathrm{T}, \mathrm{J}))=\mathrm{E}=1$;

$\operatorname{CON}(\mathrm{T}) . . \operatorname{sum}\left(\mathrm{xk}, \quad \mathrm{X}(\mathrm{T}, \mathrm{xk})^{\star} \operatorname{sum}\left(\mathrm{M}, \quad\left[\left(\mathrm{P}(\mathrm{xk}, \mathrm{M})^{\star \star} \mathrm{q}\right) / \operatorname{sum}\left(\mathrm{M}, \quad\left(\mathrm{P}(\mathrm{xk}, \mathrm{M})^{\star \star} \mathrm{q}\right)\right]^{\star} \mathrm{Z}(\mathrm{M})\right)\right)\right.$

$+\operatorname{sum}\left(\left(J,\left[W(T, j){ }^{\star \star} \mathrm{q}\right) / \operatorname{sum}\left(\left(J, W(T, j){ }^{\star \star} \mathrm{q}\right)\right]^{\star} \mathrm{V}(\mathrm{t}, \mathrm{j})\right)=\mathrm{E}=\mathrm{Y}\left(\mathrm{T},{ }^{\prime} \operatorname{lnLt} "\right) ;\right.$

$=\mathrm{E}=\mathrm{Y}(\mathrm{T}, " \operatorname{lnLt} ")$;

Model labour /ALL/;

labour.optfile $=1$;

labour.HOLDFIXED = 1 ;

labour.scaleopt $=1$;

option NLP = minos5;

Solve labour maximising OBJ using NLP;

$\mathrm{PAR}(\mathrm{xk})=\operatorname{sum}(\mathrm{M}, \mathrm{P} . \mathrm{L}(\mathrm{xk}, \mathrm{M}) \star \mathrm{Z}(\mathrm{M}))$;

DISPLAY PAR,q.l;

*in sample teoretical yy

parameter

$\operatorname{logLL}(\mathrm{T})$ in sample pronostical $\mathrm{Y}$;

$\log L L(T)=\operatorname{sum}\left(x k, X(T, x k)^{\star} \operatorname{Par}(x k)\right)$;

display logLL;

parameter

god goodness coefficient

$S(x k)$ parameter information index

et(T) estimation of random term;

$\mathrm{S}(\mathrm{xk})=\left(1-\operatorname{sum}\left(\mathrm{m}, \mathrm{P} . \mathrm{L}(\mathrm{xk}, \mathrm{M})^{\star \star} \mathrm{q} .1\right)\right) /(\mathrm{q} .1-1)^{\star}(1-\mathrm{q} \cdot 1) /\left[5^{\star \star}(1-\mathrm{q} .1)-1\right]$;

et(T) $=\operatorname{data}(" \operatorname{lnLt} ", \mathrm{~T})-\log L \mathrm{~L}(\mathrm{~T})$;

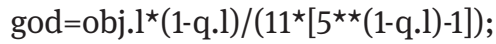

display obj.l,god, et, S, p.l,w.l; 


\section{Annex D. Recovery of Pollutant Emissions by Industrial Sector and Region: an Instructional Case}

\subsection{Introduction}

In this section, we are going to present a case that, unlike the case studies carried out in previous parts of the monograph, shows the limits of the entropy econometrics approach when some initial conditions are not fulfilled while dealing with an inverse problem. Thus, the example illustrates what should not be done to reach reliable model estimates. This is important for the less experienced modellers who try to recover information on the basis of this theory. In this instance, we see that an important property of respective continuity of probability measures of two hypotheses, as those were defined in part II of the book, is missing. In such a case, more statistical data should be collected to allow for an inference based on regular conditions. In this example, we use a GAMS code.

\subsection{Recovery of Pollutant Emission by Industrial Sector and Region: the Role of the Prior ${ }^{61}$}

Suppose we dispose of information on aggregated greenhouse emissions simultaneously at the regional and sectorial level. In Table 23 below, we can depict this total information in the last column and last row, respectively. It is important to underscore here that these two pieces of information are from two different sources and, plausibly, were initially collected for different purposes. Thus, we have to join these two pieces with the hope of recovering the real distribution state of pollutant emission by industrial sector and region. In this example, there is an additional complication related to the impossibility of comparing these two totals. In fact, values in the last column constitute an unknown aggregate of standardized quantities of different pollutants with different units of measure. Inversely, in the last row, available statistical data of aggregates have been converted into tons of $\mathrm{CO}_{2}$ equivalent. Suppose, in this problem, we are asked to recover the regional and sectorial level of greenhouse emissions in tons of $\mathrm{CO}_{2}$ on the basis of the above availability of statistical data.

If column and row totals were explained in the same unit of measure, we would then have to deal with a direct extension of the Jaynes dice problem (see Table 1 in Part II) from one to two-dimensional discrete space. In this context, finding a unique optimal solution for such a problem requires finding an equation system with a

61 For a complete solution of this problem, we send the reader to: Acta Physica Polonica A 2015, 127, A-13. [CrossRef] 
closed form. Additional and consistent a priori information is required to enable an optimization entropy device moving from uniform distribution toward an optimal, global solution. For a researcher unacquainted with solving this kind of problem, the present example aims at revealing the limitations of the maximum entropy principle when minimum conditions are not fulfilled. In this example, the a priori is uniformly distributed information of pollutant emissions by industrial sector and region. Doing so, we try then to solve the problem using the well-known principle of insufficient reason already discussed in the introduction of this work.

As already observed, in the present problem, we have in column and row totals different units of measure. In this case, we suggest introducing a scaling factor (as an additional new a priori) in consistency equations of the model, theoretically allowing the table to then balance.

\section{The Model}

According to what has been said above and then without a priori information about the system, we propose applying non-extensive maximum entropy in the criterion function under traditional restrictions such as moments and normality conditions. The model takes the following usual form:

$\max \left(H_{q}(p)\right)=\left[1-\sum_{i} \sum_{j}\left(p_{i j}\right)^{q}\right] /(q-1)$

s.t.:

$Y_{i}=c(i) \sum_{j} X_{j} p_{i j}$

$x_{i j}=X_{j} \frac{p_{i j}{ }^{q}}{\sum_{i} p_{i j}{ }^{q}}$

$1_{j}=\sum_{i} \frac{p_{i j}{ }^{q}}{\sum_{i} p_{i j}{ }^{q}}$

where:

$Y_{i}$ : means total by row $\mathrm{i}$,

$X_{j}$ : means total by column $\mathrm{j}$,

$p_{i j}$ : probabilistic structure of greenhouse emissions by region

$x_{i j}$ : quantity of pollutant emission inside cells.

In this problem, we dispose of up to 122 points to be estimated (then including an additional 17 scaling factors $c(i)$ ) and only 23 observation points. Naturally, we are dealing with an inverse problem that we know how to solve from theoretical and 


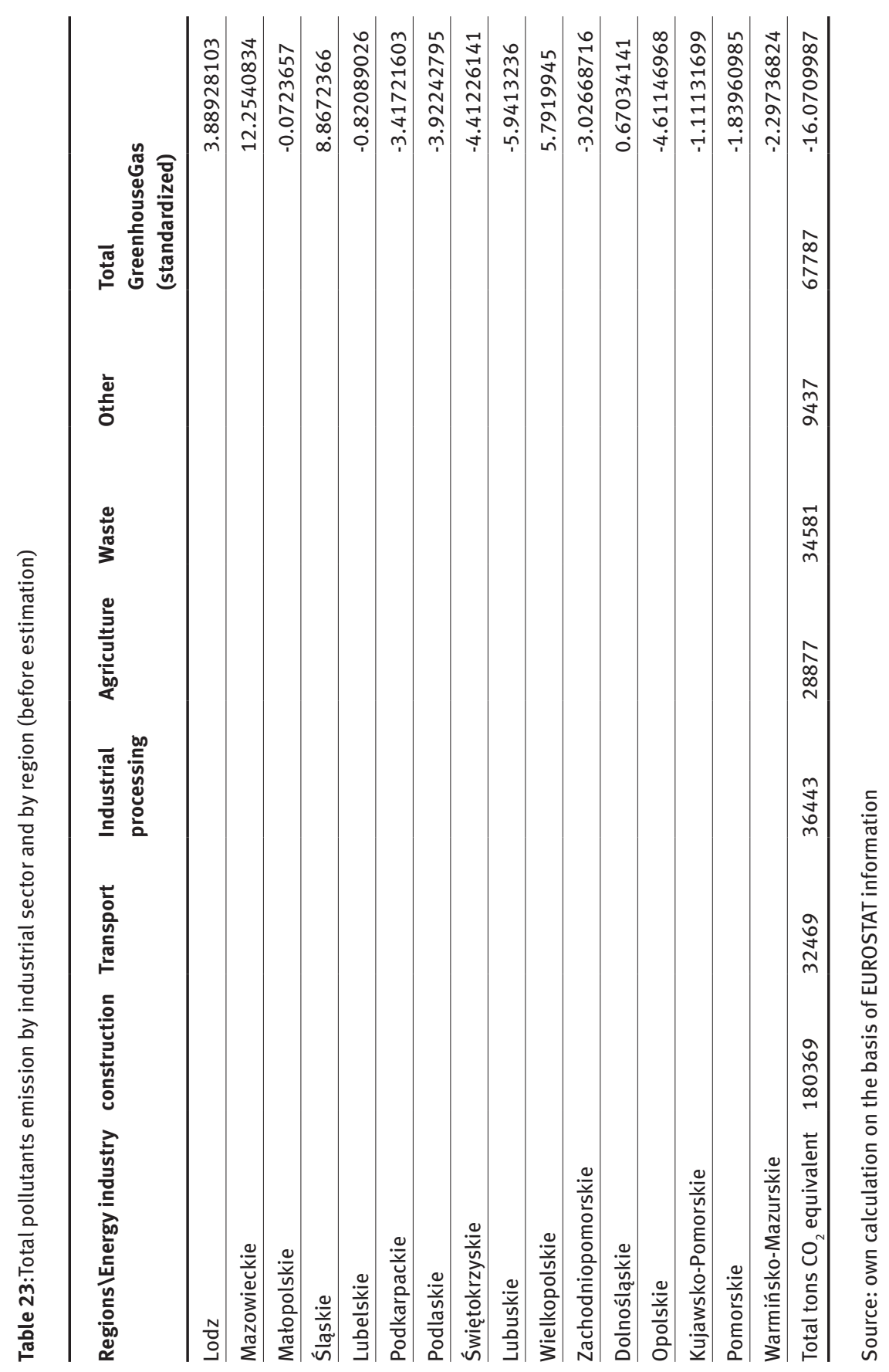


Table 24: Total pollutant emission by industrial sector and region (post entropy estimation).

\begin{tabular}{lllllllll}
\hline & indusener & indutrans & trans & procind & agr & dech & aut & Total \\
lod & 445.943 & $0.00 \mathrm{E}+00$ & $0.00 \mathrm{E}+00$ & $0.00 \mathrm{E}+00$ & 92.881 & $0.00 \mathrm{E}+00$ & $0.00 \mathrm{E}+00$ & 538.824 \\
\hline maz & 25838.76 & $0.00 \mathrm{E}+00$ & 15494.79 & 3373.983 & 2457.911 & 1027.966 & $0.00 \mathrm{E}+00$ & 48193.4 \\
\hline mal & 10463.45 & 1201.047 & 760.303 & $0.00 \mathrm{E}+00$ & 993.605 & 4634.521 & 10796 & 28848.92 \\
\hline sla & 7265.899 & 1201.05 & 10.309 & $0.00 \mathrm{E}+00$ & $0.00 \mathrm{E}+00$ & $0.00 \mathrm{E}+00$ & 44955.66 & 53432.92 \\
\hline lub & 26102.65 & 1201.046 & 2023.227 & $0.00 \mathrm{E}+00$ & $0.00 \mathrm{E}+00$ & $0.00 \mathrm{E}+00$ & $0.00 \mathrm{E}+00$ & 29326.92 \\
\hline pod & 11110.19 & 1201.047 & 1.773 & $0.00 \mathrm{E}+00$ & 2289.638 & $0.00 \mathrm{E}+00$ & $0.00 \mathrm{E}+00$ & 14602.65 \\
\hline podl & 7888.465 & 2031.926 & 20.356 & $0.00 \mathrm{E}+00$ & 753.312 & $0.00 \mathrm{E}+00$ & 942.165 & 11636.22 \\
\hline swi & 3001.472 & 1171.582 & 1934.917 & $0.00 \mathrm{E}+00$ & 2240.56 & $0.00 \mathrm{E}+00$ & 298.363 & 8646.894 \\
\hline lubu & 372.657 & 3300.148 & $0.00 \mathrm{E}+00$ & $0.00 \mathrm{E}+00$ & $0.00 \mathrm{E}+00$ & $0.00 \mathrm{E}+00$ & $0.00 \mathrm{E}+00$ & 3672.805 \\
\hline wiel & 2985.15 & 2914.626 & $0.00 \mathrm{E}+00$ & 23710.43 & 15831.89 & 2197.649 & 7562.365 & 55202.12 \\
\hline zac & 9952.093 & 691.237 & 1130.836 & 1792.583 & 2400.436 & 1352.623 & 250.21 & 17570.02 \\
\hline dol & 21697.25 & 1443.422 & 9855.435 & $0.00 \mathrm{E}+00$ & 2401.033 & 224.241 & 995.144 & 36616.52 \\
\hline opo & 7448.701 & 827.828 & 3820.23 & $0.00 \mathrm{E}+00$ & 317.823 & $0.00 \mathrm{E}+00$ & $0.00 \mathrm{E}+00$ & 12414.58 \\
\hline kuj & 25001.55 & $0.00 \mathrm{E}+00$ & 1.17 & $0.00 \mathrm{E}+00$ & 2401.077 & $0.00 \mathrm{E}+00$ & 993.112 & 28396.91 \\
\hline pom & 20794.83 & $0.00 \mathrm{E}+000$ & 5.611 & $0.00 \mathrm{E}+00$ & 2400.832 & $0.00 \mathrm{E}+00$ & 993.983 & 24195.26 \\
\hline war & $0.00 \mathrm{E}+00$ & 15284.04 & 1384.048 & $0.00 \mathrm{E}+00$ & $0.00 \mathrm{E}+00$ & $0.00 \mathrm{E}+00$ & $0.00 \mathrm{E}+00$ & 16668.09 \\
\hline & 180369 & 32469 & 36443 & 28877 & 34581 & 9437 & 67787 & \\
\hline
\end{tabular}

Source: own calculation.

empirical models encountered earlier in this work. Outputs from derivations are shown in Table 24. Only a limited part of the information has been recovered. In fact, column totals have been accurately recovered, and line totals seem, to some extent, to conform to our expectations. In fact, we see that predominant regions in greenhouse gas emissions, like Mazowieckie, Slaskie, seem to produce the highest levels of pollutants.

As already known, adding a new piece of a priori information far from uniform distribution and consistent with properties of the system would significantly improve the quality of prediction of these emission quantities. Additionally, as has been observed in the case of forecasting input-output systems (Part III), entropy estimators belong to the family of Stein estimators. As such, smaller probabilities are shrunk and higher probabilities then dominate in the space of solutions. Fortunately, adding more $a$ priori information in the model enhances parameter precision and then allows for recovering the influence of smaller events. 